\title{
Periorbital amyloid myoneuropathy: case report
}

\author{
Martha Lilia Tena-Suck ${ }^{1}$, Carlos Guillermo Patiño-Camacho ${ }^{2}$, Emmanuel Antonio Luna ${ }^{3}$ and Francisca Fernández Valverde ${ }^{4}$ \\ ${ }^{1}$ Departamento de Neuropatología, Instituto Nacional de Neurología y Neurocirugía Manuel Velasco Suárez, México \\ ${ }^{2}$ Departamento de Patología, Hospital Civil antiguo de Guadalajara Jalisco, México \\ ${ }^{3}$ Residente de Neurología, Instituto Nacional de Neurología y Neurocirugía Manuel Velasco Suárez, México \\ ${ }^{4}$ Laboratorio de Neuropatología Experimental, Instituto Nacional de Neurología y Neurocirugía Manuel Velasco Suárez, México
}

\begin{abstract}
Periorbital amyloid myopathy is a very rare tumor. A 42 year old female, presented to our hospital with ocular pain, and progressive increase in the volume of the left eye. Brain MRI showed increased density in the periorbital tissue of the left eye. Soft tissue biopsy was performed and periorbital fat with violet indurated areas was observed. Histologically hyperplastic nerve fibers were seen with tank fibrillary hypertrophic hyaline material as well as muscle fibers of the fibrillary material deposition. Fibro fatty tissue infiltrations positive to Congo red staining, also showed eosinophil fibrillary material tanks. Immunohistochemistry of the muscle fibers was positive for GLUT4, dystrophin and nerve fibers were positive for s-100. Deposits were identified in both IgG and kappa chains confirming the diagnosis of periorbital amyloid myopathy. Conclusion: Dystrophin positive come up with the possibility of amyloid to provoke to the muscle fibers with glucose metabolic disturbance.
\end{abstract}

\section{Introduction}

Amyloidosis is a rare group of diseases characterized by extracellular amyloid deposits in different organs [1,2] and is a disorder caused by an alterations in the structure of the proteins. The deposition of these proteins in tissues and organs can affect their normal function [1-3]. There are different types of amyloid, including 25 human and 8 animal fibril proteins [2], such as, transthyretin, apolipoprotein A-1, cystatin C, gelsolin, amyloid beta protein, beta 2-microglobulin, scrapie protein, and islet amyloid polypeptide etc. [3] Clinically amyloidosis has been described as localized or systemic disease, as well as, hereditary or acquired form [1-5]. The extent of amyloid deposit clinically affects organ function [1-3]. The deposition of amyloid can be of different proteins and the most common form of local amyloidosis is the local deposition of monoclonal immunoglobulin light chains produced by B-cell or plasma-cell clones. Chronic inflammatory diseases can also cause localized amyloid light chain amyloidosis [5].

Periocular and orbital amyloidosis is an extremely uncommon disease that presents with a variety of symptoms, depending on the location and depth of the amyloid deposition [5,6]. Amyloid deposition causes tissue destruction and progressive disease which effects long term survival $[3,5]$. Early identification and differentiation of the protein depositions is important for the prognosis and treatment [5].

The authors report a rare case of periorbital amyloidosis in a 42-year-old woman, who developed a periorbital mass.

\section{Clinical case}

A healthy 42 years old woman over a 3 months time period developed progressive left eye pain, diplopia, and headache with enlargement of the left periorbital. Her ophthalmologic examination showed no significant abnormalities and her vision was within normal limits. Cerebral CT scan and MRI was conducted and a left periorbital mass was identified (Figures 1a-1c). Meningioma was the preliminary diagnosis and she was subjected to surgical resection. During the surgical procedure a discrete tumor was not identified. Indurated purplish fibrous lesion affecting soft tissues with fatty infiltration was observed. Histologically observed abundant nerve fibers and skeletal muscle tissue with adipose infiltrated were seen (Figure 2a). Nerves fibers were hypertrophic and showed deposits of homogeneous eosinophilic fibrillary material without aspect of fibrosis (Figure 2b). Lymphocytic inflammatory infiltrates and plasma cells were also observed. Some vessels were thickened with the presence of fibrillary material tank (Figure 2c). Hypertrophy of type 1 and 2 fibers was found, with edema and presence of numerous nerves (Figure $2 \mathrm{~d}$ ), but no fatty infiltrations.
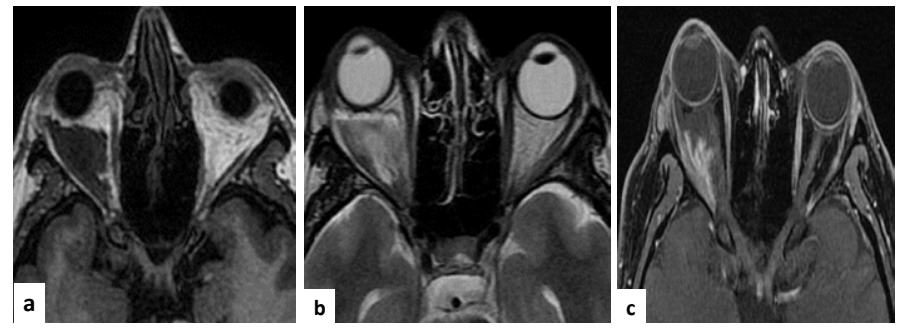

Figure 1. MRI in (a, b y c) showed the sequence in T1, T2 y T1 with gadolinium, observed proptosis of the right eyeball and intraconal secondary whish was injury, hypointenses in T1 and hyperintense in T2. It was also heterogeneous and hypointense inside that displacing the optic nerve, which elongates the external rectus muscle and infiltrates the intraconal fat. With gadolinium heterogeneous enhancement is observed with a wide base to the lateral rectus.

Correspondence to: Dr. Martha Lilia Tena Suck, Departamento de Neuropatología. Instituto Nacional de Neurología y Neurocirugía Manuel Velasco Suárez, México Av. Insurgentes sur no. 3877, colonia la joya, Delegación tlalpan, México D.F México, Tel: 56063822 ext. 2011; E-mail: mltenasuck@gmail.com

Key words: amyloidosis, periorbital injury, congo red stain, ocular injury, myopathy Received: February 09, 2015; Accepted: February 17, 2015; Published: February 20, 2015 

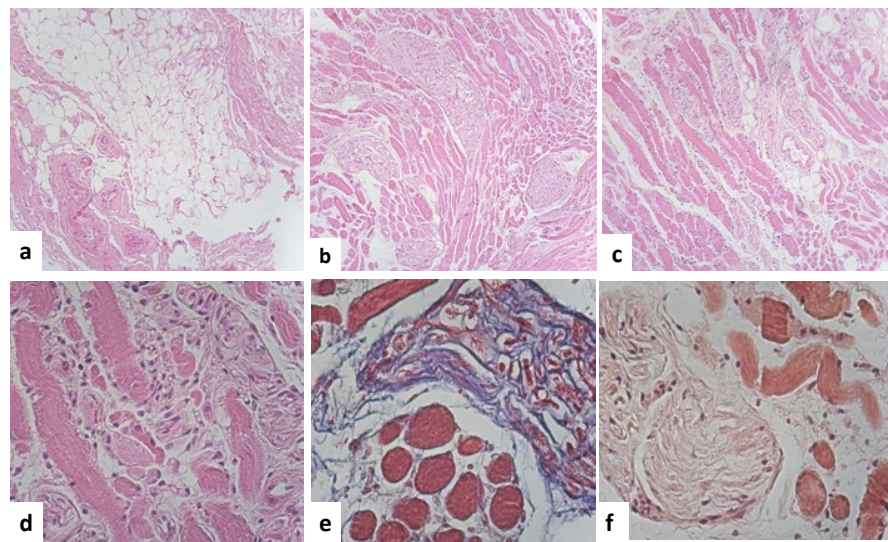

Figure 2. Histopathology features. (a) Observed nerve with different sharped and form and muscle fibers were adipocyte infiltrate. (b). The nerves were hypertrophic and showed and amyloid deposition. (c) Lymphocytic and plasma cells were also observed, some vessels showed amyloid deposition in the wall. The muscle fibers were also hypertrophic with amyloid deposition. (d) We observed that some myocytes showed central nucleus. (e) Masson stain showed the muscle fibers with amyloid deposition x400). (f) And Congo red stain showed that the muscle fibers as well as the wall of the vessels a fibrillary material deposition in brown $\mathrm{x} 400$ ).

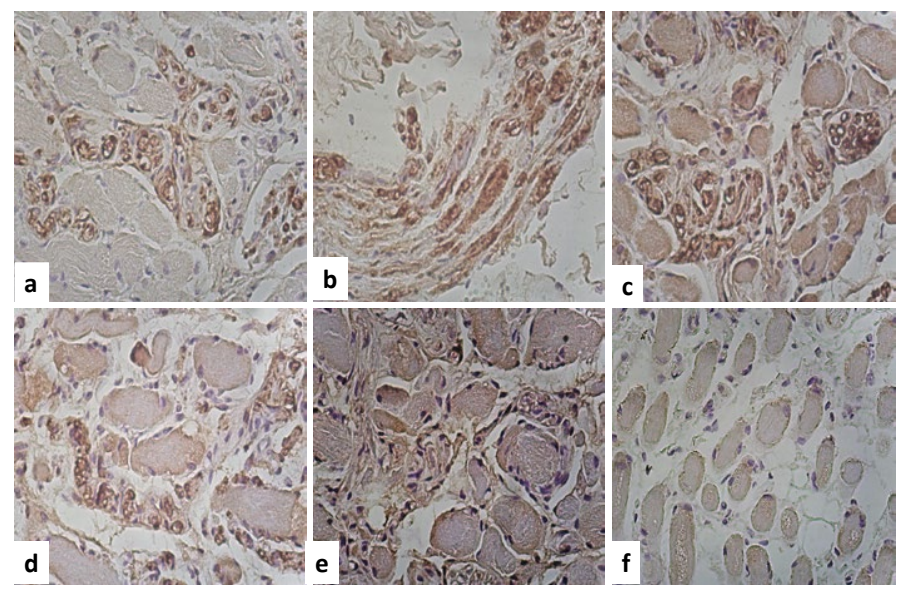

Figure 3. Immunohistochemistry. (a) S-100 protein was positive immunoreaction in the peripheral of the muscle fibers as well as the nerves (b).The nerves showed demylinization areas and amyloid deposition with an edema appearance (myelin stain IHQx400). (c) Glut-4 was positive immunoreaction in the peripheral areas of the fibers and in some round fibers. (c) IgG was immunoreaction in the wall of the vessels and around the amyloid material (d). Kappa was also positive immunoreaction in the peripheral areas of the fibers and in some round fibers and in the nerves. (f) Dystrophin 2 was positive in the peripheral areas of the fibers and in some round fibers (IHQx400).

Red Congo stain showed deposits in conjunctive tissue, related to the perimysium and endomysium of some vessels with stained deposits around the muscle fiber (Figure 2e). Immunohistochemistry was also performed and the nerves had strong positivity to s-100 protein (DAKO, dilution 1:100, Carpintery Ca) (Figures 3a and 3b), Glut-4 glucose receptor (Anti-Glucose Transporter GLUT4 antibody (ab654) dilution 1:100) was positive in the peripheral area of the muscle fibers (Figure 3c) IgG was immunoreaction positive in the vessels wall and in the fibrillary material deposition (Figure 3d), kappa(DAKO, dilution 1:100, Carpintery Ca) (Figure 3e) and dystrophin 2 (mouse monoclonal MANDYS106 rod-domain anti-dystrophin antibody, dilution 1.100) were also positive in the peripheral zone of the muscle fibers (Figure 3f). Periorbital amyloid with amyloid myopathy was diagnosed. BenceJones protein determination was negative.

\section{Discussion}

The clinical presentation of periocular and orbital amyloidosis is different, in some cases [6-9] can present with a variety of symptoms, depending on the location of the disease and the affected sites [1]. Amyloid deposition may affect the lacrimal gland, eyelid, conjunctiva, and ocular adnexa etc. Amyloid periorbital condition can be primary or secondary, local or systemic disease, accordingly and the patients should be investigated to rule out systemic involvement $[1,6]$. Conjunctival amyloidosis is the most common form, which manifests as a yellow-pink hemorrhagic mass. Periocular and orbital amyloidosis is an extremely uncommon disease and can present as a mass and can be confused with malignancy. It is important to confirm the diagnosis by histopathology [6,7].

Microscopic features of the biopsy sample revealed an amorphous, homogenous and fibrillary material deposition consistent with amyloid [1,6], ultimately to confirm the diagnosis of amyloid is the demonstration of apple-green birefringence on congo red staining [1-5].

The histochemical and immunohistochemical of the different forms of amyloidosis have been considered using different primary antibodies [4]. Antibodies against the $\mathrm{P}$ component, proteins AA, AL, FAP, ATTR, A lambda, A kappa and A beta 2 macroglobulin and possibly further types of amyloids for classification purposes, have been used with great precision [4].

Amyloid myopathy an under recognized entity, predominantly presents with progressive proximal weakness in primary amyloidosis. Muscle biopsy reveals both amyloid material as well as and lambda light chains deposits in vessel walls, but also inflammatory infiltrates. Inflammatory cell typing has been studied by immunohistochemistry stain and revealed a predominant T-helper cell infiltration as well as B-lymphocytes and plasma cells.

Amyloid deposition in muscle is a rare condition, can be primary or secondary and usually affects nerves, vascular walls and muscle fibers. The histological findings of a myopathic pattern is not specific, muscle fibers, particularly the type II variety, are diminished in size, because it can be found in several types of myopathies [11-13]. Amyloid myopathy is characterized by muscle pseudo hypertrophy and infiltration of amyloid material in the interstitium as well as within the fibers [10], as we observed in this case. Chronic myopathy can be caused by immunoglobulin light chain amyloidosis deposition $[11,12]$. Amyloid myoneuropathy can resemble inclusion body myositis $[13,14]$. Small amounts of mononuclear inflammatory cells in endomysium or perivascular spaces without invasion of nonnecrotic muscle fibers may also be seen, leading to an erroneous diagnosis of polymyositis. Polymyositis and myositis of inclusion bodies must be considered as a differential diagnosis.

Sporadic inclusion-body myositis has been associated with abnormal accumulated proteins, of amyloid-beta precursor protein and of its proteolytic fragment, amyloid-beta, while, several aberrant proteins accumulate inside muscle fibers, including $\beta$-amyloid, $\alpha$-synuclein and tau protein. Several key components of stress mechanisms of proinflammatory cells, such as nitric oxide production and macro processing autophagy contribute to muscle fiber damage associated with the aging cellular muscle fiber environment and this could be the etiology of these events [14].

We observed in our case both muscle fiber hypertrophy and that 
these fibers were immunoreaction positive for light chain kappa, immunoglobulin IgG, Glut4 and dystrophin2.

Muscle fiber is the major tissue for postprandial glucose disposal and it facilitates glucose consumption into muscle fibers, and is mediated by increases in surface membrane levels of the glucose transporter GLUT4 via insulin- and/or muscle contraction-mediated GLUT4 translocation [15]. Glucose transporter GLUT4 is a larger regulator of glycemic homeostasis in skeletal muscle that is usually trapped at perinuclear spaces of myocytes. Systemic inflammation is a major risk factor for critical-illness myopathy, and could be activates by inflammation mediator NF- $\kappa \mathrm{B}$ and interleukin 6 , that mediate and regulate GLUT4 $[15,16]$. However, it is well known that the amyloid A (A-SAA) is associated with insulin resistance [17]. Therefore, we hypothesize that the expression of GLUT4 and anti-dystrophin 2 could be in association with the same muscle fiber damage [18].

In conclusion, we present a rare case of periorbital amyloidosis with myopathy, and myeloid deposit was associated with the expression of IgG, kappa light chain, dystrophin and glucose receptor Glut4 in a patient which presented as with a progressive increase in volume of the left orbit with mass effect and loss of vision.

\section{References}

1. Hassan W, Al-Sergani H, Mourad W, Tabbaa R (2005) Amyloid heart disease. New frontiers and insights in pathophysiology, diagnosis, and management. Tex Heart Inst J32: 178-184. [Crossref]

2. Westermark P, Benson MD, Buxbaum JN, Cohen AS, Frangione B, et al. (2005) Amyloid: toward terminology clarification. Report from the Nomenclature Committee of the International Society of Amyloidosis. Amyloid 12: 1-4. [Crossref]

3. Cohen AS, Jones LA (1991) Amyloidosis. Curr Opin Rheumatol 3: 125-138. [Crossref]

4. Bély M, Apáthy A (2000) Histochemical and immunohistochemical differential diagnosis of amyloidosis--a brief illustrated essay and personal experience with Romhányi’s method. Amyloid 7: 212-217. [Crossref]

5. Bestard Matamoros O, Poveda Monje R, Ibernon Vilaró M, Carrera Plans M, Grinyó
Boira JM (2008) Systemic AA amyloidosis induced by benign neoplasms. Nefrologia 28: 93-98. [Crossref]

6. Leibovitch I, Selva D, Goldberg RA, Sullivan TJ, Saeed P, et al. (2006) Periocular and orbital amyloidosis: clinical characteristics, management, and outcome. Ophthalmology 113: 1657-1664. [Crossref]

7. Aryasit O, Preechawai P, Kayasut K (2013) Clinical presentation, treatment, and prognosis of periocular and orbital amyloidosis in a university-based referral center. Clin Ophthalmol 7: 801-805. [Crossref]

8. Naxer S, Behnes CL, Schittkowski MP (2011) Amyloidosis-a rare differential diagnosis of an orbital tumour. Klin Monbl Augenheilkd 228: 555-564. [Crossref]

9. Yerli H, Aydin E, Avci S, Haberal N, Oto S (2011) Focal Amyloidosis of the Orbi Presenting as a Mass: MRI and CT Features. Iran J Radiol 8: 241-244. [Crossref]

10. Scola RH, Werneck LC, Ramos CS, Pasquini R, Graf H, et al. (2001) Amyloidotic muscle pseudohypertrophy: case report. Arq Neuropsiquiatr 59: 582-586. [Crossref]

11. Manoli I, Kwan JY, Wang Q, Rushing EJ, Tsokos M, et al. (2013) Chronic myopathy due to immunoglobulin light chain amyloidosis. Mol Genet Metab 108: 249-254. [Crossref]

12. Ohtsuka Y, Yasui N, Sekiguchi K, Kowa H, Nishino I, et al. (2012) Case of amyloidosis with amyloid deposition detected only in skeletal muscles. Rinsho Shinkeigaku 52 739-743. [Crossref]

13. Abuzinadah AR, Joseph JT, Korngut L (2013) Amyloid myoneuropathy mimicking inclusion body myositis. Can J Neurol Sci 40: 255-258. [Crossref]

14. Schmidt J, Dalakas MC (2013) Inclusion body myositis: from immunopathology and degenerative mechanisms to treatment perspectives. Expert Rev Clin Immunol 9: 11251133. [Crossref]

15. Lauritzen HP, Schertzer JD (2010) Measuring GLUT4 translocation in mature muscle fibers. Am J Physiol Endocrinol Metab 299: E169-179. [Crossref]

16. Weber-Carstens S, Schneider J, Wollersheim T, Assmann A, Bierbrauer J, et al. (2013) Critical illness myopathy and GLUT4: significance of insulin and muscle contraction. Am J Respir Crit Care Med 187: 387-396. [Crossref]

17. Filippin-Monteiro FB, de Oliveira EM, Sandri S, Knebel FH, Albuquerque RC et al. (2012) Serum amyloid A is a growth factor for 3T3-L1 adipocytes, inhibits differentiation and promotes insulin resistance. Int $J$ Obes (Lond) 36: 1032-1039. [Crossref]

18. Wagner PD (2001) Skeletal muscle angiogenesis. A possible role for hypoxia. $A d v \operatorname{Exp}$ Med Biol 502: 21-38. [Crossref]

Copyright: (C2015 Tena-Suck ML. This is an open-access article distributed under the terms of the Creative Commons Attribution License, which permits unrestricted use, distribution, and reproduction in any medium, provided the original author and source are credited. 